\title{
Deliberacionismo e os limites da crítica: uma resposta
}

\begin{tabular}{c}
\hline \hline Luis Felipe Miguel \\
Instituto de Ciência Política \\
Universidade de Brasília \\
\hline \hline
\end{tabular}

\begin{abstract}
Resumo: O artigo apresenta uma resposta ao texto "Teoria crítica e democracia deliberativa", de Ricardo Fabrino Mendonça (Opinião Pública, vol. 19, n 1). Em vez de analisar a fidelidade das atuais teorias democrático-deliberativas ao legado da Escola de Frankfurt, busca-se compreender o quanto elas mantêm do impulso emancipatório original. A avaliação é que a teoria deliberativa encontra-se presa a um trade-off entre uma normatividade abstrata, incapaz de uma intervenção efetiva na realidade, e a acomodação com as instituições e práticas das democracias liberais realmente existentes.
\end{abstract}

Palavras-chave: Democracia deliberativa; Teoria democrática; Teoria crítica

Abstract: The article presents a response to the text "Critical theory and deliberative democracy" by Ricardo Mendonça Fabrino (Opinião Pública, vol. 19, $\mathrm{n}^{\circ} 1$ ). Instead of analyzing the fidelity of current democratic-deliberative theories to the legacy of the Frankfurt School, it seeks to understand how much they retain from their original emancipatory impulse. The assessment is that the deliberative theory is tied to a trade-off between an abstract normativeness, incapable of effective intervention in reality, and the accommodation with the institutions and practices of really existing liberal democracies.

Keywords: Deliberative democracy; Democratic theory; Critical theory 
No artigo "Teoria crítica e democracia deliberativa: diálogos instáveis", Ricardo Fabrino Mendonça empreende uma discussão sobre a fidelidade da teoria democrática deliberativa às suas origens frankfurtianas, concluindo por uma resposta ambígua, escorada na multiplicidade e variedade de vertentes que hoje estão abrigadas sob o rótulo abrangente da "democracia deliberativa" 1 . Logo no início, o artigo é apresentado como uma resposta a questões que eu havia formulado numa discussão com o autor, alguns anos atrás (MENDONÇA, 2013, p. 50). Trata-se, portanto, de uma oportunidade para que eu esclareça não apenas as divergências com as soluções apontadas por Mendonça, mas também as insuficiências que percebo no empreendimento da teoria deliberativa em geral.

Minha questão é apresentada, no artigo a que respondo aqui, como sendo uma preocupação com o desvanecimento do teor crítico da deliberação e sua acomodação ao liberalismo, o que corresponde bastante bem à posição que tenho desenvolvido nos últimos anos (MIGUEL, 2002; 2005; 2011 ; 2014a). No entanto, a resposta de Mendonça a interpreta de uma forma que não corresponde à minha intenção. Usei "crítico" não como referência a uma tendência particular de pensamento, a "teoria crítica", nascida da Escola de Frankfurt, mas de maneira descritiva. Referia-me àquelas reflexões sobre o mundo social que não se acomodam à sua conformação atual; ao contrário, guardam o estranhamento em relação a ele $^{2}$, investigam os padrões de dominação presentes e, no mesmo movimento, identificam os espaços de resistência, efetivos ou latentes, e os horizontes de transformação em potencial.

Assim, a própria teoria crítica (frankfurtiana) pode ver questionada sua qualidade crítica, na medida em que bloqueia ou realiza de forma insatisfatória algum dos elementos presentes no entendimento descritivo do que é um pensamento crítico. Enquanto a abordagem que busca identificar a permanência da escola da teoria crítica nas vertentes atuais da democracia deliberativa tem um interesse escolástico, o caminho que escolho possui a relevância teórico-política que os próprios frankfurtianos de primeira geração, aliás, desejavam para seu trabalho. Está em jogo a capacidade desta corrente - a democracia deliberativa - para interpretar o mundo e orientar sua transformação em sentido emancipatório.

Nas páginas que se seguem, organizo meu argumento em três eixos, que correspondem às três partes em que se divide este artigo. O primeiro eixo aponta que a incorporação de outros padrões discursivos, além do argumento racional, nos "giros" mais recentes da teoria deliberativa rebaixa fortemente seu ideal normativo, sem ser capaz de promover de fato a "inclusão" desejada. O segundo eixo indica que a incorporação lateral do conflito político nos modelos deliberativos não é suficiente para descaracterizar seu pré-maquiavelismo de origem, uma vez que o conflito continua sendo visto como uma externalidade e que o problema da dominação não é enfrentado. O terceiro eixo trata do crescente institucionalismo da literatura deliberativa, que ignora que estratégias disruptivas são frequentemente o

\footnotetext{
1 Agradeço a leitura prévia e as críticas e comentários de Flávia Biroli e de Regina Dalcastagnè a este artigo. Permaneço, é claro, como único responsável por seus defeitos.

2 O estranhamento que é "um antídoto eficaz contra um risco a que todos nós estamos expostos: o de banalizar a realidade" (GINZBURG, 2001 [1998], p. 41).
} 
OPINIÃO PÚBLICA, Campinas, vol. 20, n 1, abril, 2014, p. 118-131

meio mais eficaz de ação para os grupos em posição subalterna. A conclusão, por fim, sugere que a crescente acomodação da teoria democrática deliberativa dentro dos limites do ordenamento político liberal e concorrencial é coextensiva à redução dramática da voltagem crítica da elaboração teórica dos herdeiros mais reconhecidos da Escola de Frankfurt, sobretudo o Habermas de Direito e democracia em diante e Axel Honneth.

\section{Discurso e exclusão}

A primeira das três críticas às teorias deliberativas enfrentada no artigo de Mendonça é apresentada sob a fórmula "a deliberação reforça a ordem existente" (MENDONÇA, 2013, p. 53). Eu prefiro um enunciado mais moderado, mas mais preciso: a teoria deliberativa é cega aos obstáculos centrais à democratização da ordem existente. Com isso, a questão é deslocada dos efeitos de um fenômeno cuja existência empírica é contestável (a "deliberação" dos teóricos deliberacionistas) para o potencial explicativo de uma corrente de pensamento. Esse potencial, diz a crítica, é reduzido devido à insensibilidade às desigualdades centrais presentes no mundo social e aos mecanismos estruturais que garantem sua reprodução.

É uma crítica que brota já a partir das primeiras versões da democracia deliberativa e tem como focos tanto a compreensão da natureza das trocas linguísticas que a embasa quanto o modelo ideal de esfera pública que a orienta ${ }^{3}$. Começo pelo segundo destes focos. Em Mudança estrutural da esfera pública, que foi uma inspiração crucial para a geração inicial de teóricos democráticodeliberativos, Habermas (1984 [1962]) apresenta um relato edulcorado dos fluxos comunicativos na esfera pública burguesa setecentista e oitocentista, na qual imperaria a igualdade entre os interlocutores, todos colocados na situação similar de cidadãos privados com interesse em questões públicas. As exclusões de trabalhadores ou de mulheres não deixam de ser percebidas, mas são vistas como elementos contingentes - e não estruturantes desta esfera.

Naquela que foi talvez a abordagem crítica singular de maior impacto sobre a noção da esfera pública habermasiana, Nancy Fraser (1992) indicou como a esfera pública, a despeito de sua aparente neutralidade e universalidade, incorporava suposições burguesas e masculinistas. Ela constituiu-se como um espaço que os grupos em posição social subalterna não conseguiriam disputar. Com isso, a compreensão da esfera pública burguesa como imagem da "boa política" fica bem mais matizada. 0 esforço dos teóricos deliberacionistas - ao qual se soma o próprio Habermas (1997 [1992]), quando apresenta sua versão mais completa de uma teoria da democracia - é produzir um modelo mais poroso de esfera pública, capaz de abrigar os diferentes grupos, o que culminou na dissolução da ideia de uma esfera pública unificada e, mais recentemente, na noção de um "sistema deliberativo" plural, com múltiplos centros relativamente autônomos (MANSBRIDGE et al, 2012; FARIA, 2012).

A existência de uma multiplicidade de públicos, no entanto, apenas recoloca em outro patamar o problema das assimetrias no controle de recursos de poder. Pode ser que existam esferas

\footnotetext{
3 Ao longo deste artigo, salvo indicação em contrário, refiro-me às teorias democráticas deliberativas de inspiração habermasiana. São elas as mais influentes no debate internacional (e mais ainda no debate brasileiro) e também as privilegiadas no artigo de Mendonça.
} 
públicas em todo canto, de bares a concertos de rock, como quer Habermas (1997 [1992], vol. 2, p. 107), ainda que, mais provavelmente, esta percepção implique no esvaziamento completo do conceito. Mas a questão continua sendo a capacidade diferenciada que os grupos têm de influenciar nos processos de tomada de decisão e na fixação das regras que regem a vida coletiva. Dito de outra forma, diferentes "esferas públicas" têm diferentes graus de efetividade e importa saber que grupos têm acesso a quais espaços.

Essa questão é especialmente grave, no caso de Habermas de Direito e democracia, por sua adesão ao modelo sociológico conservador de Bernhard Peters. Graças a ela, como mostrou Scheuerman (1999, p. 164), a distinção crítica entre públicos fortes e públicos fracos, herdada de Fraser, é sobreposta à distinção funcional entre o centro do sistema político, com capacidade decisória, e uma periferia de associações da sociedade civil e grupos de pressão, cuja influência é e deve ser sempre mediada. No mesmo processo, é abandonada a denúncia sobre a colonização do mundo-davida pelos operadores sistêmicos, central no impulso crítico de Habermas desde Mudança estrutural até Teoria do agir comunicativo (HABERMAS, 2003 [1981]). A ação comunicativa e o direito passam a ser vistos como garantidores da integração da sociedade, num modelo em que as tensões entre os diferentes tipos de racionalidade e entre as esferas sistêmica e do mundo-da-vida tornam-se bem mais brandas (ou mesmo desaparecem), dando lugar a uma perspectiva mais harmônica, de mera diversificação funcional (cf. Cook, 2001).

O resultado é uma percepção pouco distante das narrativas democráticas elitistas, em que a capacidade de influência das pessoas comuns está suficientemente garantida com a combinação entre pluralismo social e direito de voto e a expertise da minoria de tomadores efetivos de decisão deve ter espaço garantido para se efetivar. No modelo habermasiano, a opinião pública se transforma em "poder comunicativo" por meio das eleições e, no passo seguinte, em "poder administrativo" por meio da legislação (HABERMAS, 1997 [1992], vol. I, p. 189-90). Mesmo teóricos deliberativos percebem o quanto essa narrativa é incapaz de apreender a dinâmica real do processo político e o peso que as desigualdades sociais têm nela (DRYZEK, 2000, p. 25-6).

O passo complementar para garantir a inclusão de todos nos processos deliberativos, ao lado desta multiplicação de "públicos fracos", foi o abrandamento ou mesmo a revogação da primazia concedida ao argumento racional, o que se relaciona ao primeiro foco de crítica que mencionei antes: a compreensão da natureza da linguagem. Habermas opera com um entendimento da linguagem como ferramenta emancipatória, cujo telos é sempre a obtenção do consenso, de uma forma em que seus elementos ilocucionários, capazes de promover uma comunicação interpessoal transparente, sempre são mais valorizados do que os perlocucionários (cf. Habermas, 1989 [1983]). É a aposta em uma "separação implausível do que são, de fato, elementos inextricavelmente entrelaçados numa interação linguística" (MCNAY, 2008, p. 83).

Em concordância com esse entendimento sobre a linguagem, as versões iniciais da teoria democrática deliberativa privilegiam o argumento racional - movimento, aliás, para o qual convergem amplamente também os autores inspirados em Rawls (cf. Cohen, 1997). Se, nas trocas discursivas, apenas as razões são levadas em conta, as desigualdades de status entre os interlocutores deixam de exercer efeitos. Ao mesmo tempo, os interesses egoístas não têm como se manifestar, já que se 
OPINIÃO PÚBLICA, Campinas, vol. 20, n 1, abril, 2014, p. 118-131

expressam na forma da vontade, não da razão. Com isso, o caminho para a obtenção de consensos legítimos ficaria desobstruído. A primazia da razão ocupa, assim, um lugar central na arquitetura do deliberacionismo de primeira geração.

No entanto, o modelo pressupõe que a capacidade de produção de "argumentos racionais" está igualmente distribuída entre os diversos grupos sociais, como se o argumento racional fosse uma derivação automática de uma razão humana universal e não o produto da adequação a determinados códigos. Integrantes dos grupos dominados têm, tipicamente, menor familiaridade com estes códigos e, portanto, a exigência de argumentação racional trabalha contra a atenção a seus discursos:

\footnotetext{
"Embora os deliberadores sempre decidam desconsiderar alguns argumentos, quando esta desconsideração é sistematicamente associada aos argumentos apresentados por quem nós já sabemos que está sistematicamente em desvantagem, nós deveríamos pelo menos reavaliar nossas suposições sobre o potencial democrático da deliberação. Ele não exige apenas igualdade de recursos e a garantia de igual oportunidade para articular argumentos persuasivos, mas também igualdade na "autoridade epistemológica", na capacidade de despertar reconhecimento pelos seus argumentos" (SANDERS, 1997, p.349).
}

Em resposta a tais críticas, os teóricos da democracia deliberativa vão admitir a legitimidade de um crescente número de outras formas de expressão, ao lado do argumento racional. A saudação, a retórica, o testemunho ou mesmo a fofoca podem ser "deliberativos" (YoUNG, 2000; DRYZEK, 2000). É possível perguntar até que ponto estas fronteiras podem ser estabelecidas com tamanha clareza - onde começa a retórica e termina o argumento ou se razão e emoção são mesmo tão facilmente separáveis . e também se a questão principal não seria discutir a efetividade de diferentes modos de discursos nos embates políticos, em vez de fazer listagens daquilo que é bom e daquilo que é mau, baseadas num normativismo que não se preocupa em estabelecer conexões com o mundo real. Mas, para os propósitos da presente discussão, importa assinalar que a redução da centralidade do argumento racional fere de morte o projeto habermasiano original, condenando a pretensão de universalidade das trocas comunicativas que ele descreve (MCNAY, 2008, p. 97), sem com isso resolver o problema das exclusão e da desconsideração às vozes dos grupos subalternos.

As assimetrias entre grupos situados em diferentes posições do espaço social não se reduzem à posse dos instrumentos que permitem produzir algo que apareça, na esfera pública, como um "argumento racional". Pesam, em primeiro lugar, as desigualdades materiais, que retiram dos grupos subalternos recursos necessários para a ação política (e a intervenção no debate), a começar pelo tempo livre. Os modelos deliberativos sempre operam "como se" tais desigualdades pudessem ser deixadas de lado. No entanto, são elas que apresentam os desafios centrais para a construção de uma ordem política que se aproxime da ideia de democracia como autonomia coletiva.

O peso destas desigualdades continua a se manifestar até mesmo nos modos dos discursos. Ao contrário do que estes modelos parecem indicar, os debates públicos não ocorrem no vácuo. Eles ocorrem em espaços sociais estruturados, capazes de impor ônus ou vantagens de acordo com a adequação a expectativas e/ou normas tácitas que, por sua vez, refletem as hierarquias vigentes. 
Assim, o campo político exige o manejo de determinados modos de discurso, em detrimento da expressão dos dominados. Como observou Pierre Bourdieu, "a linguagem dominante [no campo político] destrói, ao desacreditá-lo, o discurso político espontâneo dos dominados: não Ihes deixa outra opção que não o silêncio ou a linguagem emprestada, cuja lógica não é mais a do uso popular, sem ser a do uso culto, linguagem enguiçada, onde as 'palavras elevadas' estão presentes apenas para assinalar a dignidade da intenção expressiva e que, nada podendo transmitir de verdadeiro, de real, de 'sentido', priva quem fala da experiência mesma que julga exprimir" (BouRdieu, 1979, p. 538; cf. tb. Miguel, 2014a, cap. 4).

De maneira mais ampla, é posssível dizer que a crítica à racionalidade como parâmetro normativo não pode ter como limite o reconhecimento de outras formas de expressão. Seria necessário avançar na crítica às estruturas e divisões que reproduzem a lógica atual no acesso aos recursos expressivos e à valorização diferenciada de diferentes modos linguísticos e de raciocínio ${ }^{4}$.

O "giro" da democracia deliberativa, que permitiu a incorporação de formas discursivas para além do argumento racional, não chegou sequer a percorrer toda a crítica da sociolinguística aos privilégios concedidos à norma culta. Menos ainda a compreender o vínculo entre as hierarquias permanentemente atuantes, que concedem legitimidade variável aos diferentes padrões de fala, e o acesso a determinados espaços sociais. Vale lembrar da crítica de Bourdieu a Labov: não basta dizer que a fala dos guetos negros possui uma estrutura tão sofisticada quanto a que os estudantes de Harvard falam, sem lembrar que a linguagem destes últimos "abre todas as portas, notadamente as de Harvard, ao passo que as invenções linguísticas mais surpreendentes dos primeiros continuam totalmente desprovidas de valor no mercado escolar e em todas as outras situações sociais do mesmo tipo" (BOURDIEU, 1994, p. 232). Em suma, impõe-se a questão da eficácia diferenciada e socialmente produzida dos diferentes modos expressivos.

Os meios de comunicação de massa são outro espaço privilegiado do debate público em que há assimetrias marcantes quanto à possibilidade de acesso e de visibilização de posições políticas. 0 controle da mídia por grupos minoritários é um dos pontos de estrangulamento das democracias. Muito da pesquisa empírica sobre deliberação, hoje, foca a interação em fóruns da internet ${ }^{5}$, o que indica a adesão à crença, disseminada em certos círculos, de que as novas tecnologias teriam superado o problema do controle da informação. No entanto, por mais que a internet permita a formação de redes alternativas, os grandes veículos continuam provendo a esmagadora maioria das informações de que o público dispõe, controlam recursos de credibilidade que os colocam em posição vantajosa e continuam sendo, por isso, um ambiente central onde o debate público ocorre, sofrendo a influência de seus controladores.

O protagonismo concedido à internet tem também outra razão. Ele denota a aposta renitente do deliberacionismo naquilo que se poderia chamar de mito do discurso incorpóreo. Se, antes, a

\footnotetext{
${ }^{4}$ Sou grato a Flávia Biroli por ter chamado minha atenção para este ponto.

5 Só no ambiente acadêmico brasileiro são dezenas ou mesmo centenas de trabalhos. Para exemplos significativos, ver Marques (2006), Sampaio, Maia e Marques (2010), Mendonça e Cal (2012), Mendonça e Pereira (2012) e Sampaio, Barros e Morais (2012).
} 
OPINIÃO PÚBLICA, Campinas, vol. 20, n 1, abril, 2014, p. 118-131

exclusividade dada ao argumento racional alimentava a ilusão de que todos os elementos "externos" ao discurso, como a posição social ou os recursos controlados pelos falantes, seriam deixados de lado, agora é a aparente horizontalidade e mesmo o possível anonimato ou até impostura nas interações nas redes que propiciariam a dissociação entre fala e falante. No entanto, as marcas de classe, gênero e outras estão presentes na própria fala e ainda mais na escrita, operando permanentemente no sentido de diferenciar a recepção concedida às mensagem e atualizar as hierarquias sociais vigentes (BICKFORD, 1996).

O rebaixamento do ideal deliberativo não implicou numa ruptura efetiva com o irrealismo de muitas de suas premissas. Permanece uma compreensão idealizada das trocas linguísticas, que ignora como elas são estruturadas pelas hierarquias sociais, e a fantasia de que elas podem operar com as desigualdades colocadas "entre parênteses" - isto é, permanece de pé aquilo que motivava a crítica de Fraser (1992) ao conceito de esfera pública. Com isso, a teoria continua incapaz de assimilar de forma densa o peso destas desigualdades e da dominação social na dinâmica política e no funcionamento das instituições democráticas.

\section{Conflito, dominação e subjetividade}

A acomodação da deliberação às instituições existentes é a segunda das críticas contempladas por Mendonça (2013, p. 55). Vou discutir dois diferentes aspectos dela nesta e na próxima seção deste artigo ${ }^{6}$. De fato, cada vez mais parece que a deliberação não é uma alternativa, mas um elemento atuante no ordenamento político liberal. Já no Direito e democracia, de Habermas (1997 [1992]), a teoria deliberativa deixa de aparecer como uma contestação para se tornar uma justificação do liberalismo e da democracia concorrencial. As palavras de Seyla Benhabib são de clareza invejável: "A teoria da democracia deliberativa não é uma teoria em busca de prática; antes, é uma teoria que pretende elucidar, melhor do que outras, alguns aspectos da lógica das práticas democráticas existentes" (BENHABIB, 2007 [1994], p. 75).

A rigor, a própria democracia é cada vez mais dispensável ao modelo. Talvez Daniel A. Bell seja um autor atípico, com sua crença de que os regimes autoritários da Ásia são o melhor espaço para as práticas deliberativas, entre outros motivos graças ao 'forte suporte social ao 'elitismo político' ou à ideia de que o poder político deve ser concedido a elites intelectuais e éticas" (BELL, 1999, p. 76). Mas é John Dryzek, nome central na corrente, de irrepreensíveis credenciais habermasianas e identificado, aliás, com suas franjas mais críticas, quem identifica a pujança dos mecanismos deliberativos na ditadura chinesa e chega a identificar um "caminho deliberativo para a democratização" naqueles países que "resistem à democracia" (sic) (DRYZEK, 2010, p. 16).

O veredito de Mendonça é que, "se, de fato, a tendência de alguns pesquisadores em aceitar a democracia existente evidencia uma perda do teor crítico, isso não é consequência imediata e

\footnotetext{
${ }^{6}$ Não vou me deter na terceira crítica, o fato de que "a guinada empírica aproximou a abordagem deliberacionista da teoria tradicional” (MENDONÇA, 2013, p. 56), por julgar que, naquilo que ela possui de mais relevante, é uma derivação da segunda. A onda de estudos que buscam "medir" os graus de deliberação disto ou daquilo, à parte as simplificações de operacionalização e o fetichismo quantitativista, tem como pressuposto a aceitação do ordenamento institucional dado e o isolamento dos eventuais espaços deliberativos (muitas vezes, uma vez mais, na internet) das desigualdades sociais circundantes.
} 
necessária da matriz teórica" deliberacionista (MEndonçA, 2013, p. 60). A sentença é demasiado cuidadosa, falando em "alguns pesquisadores" para se referir a algo que é, seguramente, uma démarche amplamente majoritária na corrente. Tampouco é essencial discutir se foi uma "consequência inevitável" ou, ao contrário, o fruto de concessões e adaptações a pressões e incentivos que partiram, por exemplo, do próprio Estado, hoje consumidor prioritário de uma série de engenharias deliberativas que movimentam um mercado que não é desprezível ${ }^{7}$. O ponto é que tais desdobramentos são coerentes com aspectos que não são secundários do deliberacionismo inicial.

Minha hipótese, que no entanto ainda precisa ser investigada com maior profundidade, é que, para o deliberacionismo de origem, o principal obstáculo à acomodação com a ordem liberal não estava na vigência da dominação, mas na impossibilidade de alcançar o consenso. No momento em que as injunções do realismo motivaram o abandono do ideal de consenso, estava aberto o caminho para a aceitação do modelo liberal. Até porque a incorporação do conflito foi feita de uma forma tímida, que permanece bloqueando a compreensão do caráter antagônico das diferenças políticas centrais e passando ao largo da questão da dominação social.

O reconhecimento de que não é razoável pretender que as interações na arena política produzam consensos é o principal trunfo das teorias deliberativas recentes para demonstrar seu crescente realismo. Negociação, compromisso e barganha entraram no rol dos resultados "admissíveis", uma alteração que James Bohman (1998) já apontava como a mais importante mudança no interior da corrente. O estatuto desses resultados, no entanto, permanece ambíguo. Sua admissibilidade transita como um tributo às falhas da natureza humana, à nossa incapacidade de obter de maneira sistemática o consenso genuíno - um pouco como, para Rawls [2005 [1993]), são os "limites da razão" que nos condenam ao pluralismo de doutrinas razoáveis.

O mais importante, porém, é que a incorporação do conflito - sempre como um elemento externo à natureza das trocas linguísticas - não inclui a dominação. Enquanto questão de fato, é indiscutível que barganhas e negociações são o resultado alcançado nas disputas políticas reais. Julgar que elas são normativamente admissíveis, porém, só é possível com a abstração das assimetrias que afetam os envolvidos na negociação, em termos dos recursos materiais e simbólicos que controlam. Uma barganha só é justa se aqueles que dela participam são igualmente capazes de proteger seus próprios interesses. E quando os agentes estão ligados por relações de dominação, o objetivo não pode ser a negociação justa, nem mesmo o consenso, mas sim a superação da própria dominação.

Sem entrar numa discussão conceitual minuciosa, que tomaria mais espaço do que aquele de que disponho no momento, é possível definir "dominação" como sendo a situação em que um agente define, unilateralmente e em seu próprio benefício, as circunstâncias em que outro agente se move, de maneira a perpetuar uma distribuição assimétrica das vantagens materiais e/ou simbólicas. Isso inclui os próprios processos de formação das preferências, pesadamente constrangidos pelo controle dos mecanismos de difusão das representações do mundo social.

\footnotetext{
${ }^{7}$ Um autor secundário, James Fishkin, foi pioneiro ao registrar o que chamou de "Deliberative Polling TM", um empreendimento comercial-político-midiático-acadêmico. As primeiras experiências com o produto estão descritas em Fishkin (1997). Cabe assinalar que Mendonça não ignora, em seu artigo, a emergência deste mercado.
} 
OPINIÃO PÚBLICA, Campinas, vol. 20, nº 1, abril, 2014, p. $118-131$

A teoria deliberativa tem como principal mérito romper com a visão liberal utilitarista de preferências fixas e "naturais", mas falha ao não entender que as desigualdades na capacidade de influenciar a produção das preferências operam também nas esferas discursivas por ela louvadas. A privação material reduz o horizonte de expectativas; o acesso menor à informação limita a possibilidade de produção de alternativas; o controle dos veículos de difusão dos conteúdos expressivos molda valores e ambições. A crítica frankfurtiana à indústria cultural é um exemplo, a análise feminista sobre a produção da acomodação das mulheres aos papéis convencionais de gênero é outro. O salvo conduto concedido à barganha em nada altera essa situação.

Assim, ao incorporar uma visão do conflito que passa ao largo da dominação, o novo deliberacionismo recai na vala comum do pluralismo liberal, sem superar os limites que seu apego anterior ao consenso estabelecia. Daqui se chega a uma questão de fundo, vinculada à aposta persistente no potencial emancipador das trocas discursivas intersubjetivas. Em toda a teoria deliberativa, assim como nos desdobramentos recentes das teorias do reconhecimento de viés honnethiano, quaisquer relações de dominação (ou mesmo, em sentido amplo, de poder) são externas à formação dos sujeitos. Só partindo desse pressuposto é que se pode chegar à crença de que os acordos e consensos obtidos de forma voluntária são necessariamente legítimos e refletem, se não um interesse geral, ao menos o equilíbrio não enviesado entre os interesses existentes.

No entanto, a disjunção entre poder ou dominação e formação da subjetividade é insustentável. O caráter produtivo do poder se manifesta, em primeiro lugar, no estabelecimento dos sujeitos. Seja por meio do mecanismo da "interpelação" identificado por Althusser (1976), seja recorrendo às noções de habitus e violência simbólica, de Bourdieu (1980; 1997), seja ainda lançando mão da teoria feminista (MACKINNON, 1989), existem inúmeras vias para compreender porque as relações de dominação não são externas aos sujeitos ${ }^{8}$. Como observou uma autora simpática à corrente, mas que manteve com ela uma relação complexa, uma teoria democrática centrada na discussão precisa desenvolver entendimento sobre o funcionamento da ideologia (YoUNG, 2001, p.687). Sem admitir isso, o deliberacionismo se prende a uma compreensão abstrata, ingênua e sociologicamente indefensável das relações humanas. Mas, se o admitir, terá que rever de maneira profunda todo o seu edifício teórico.

\section{Ação discursiva e ativismo}

Assim, a teoria deliberativa é presa de uma percepção ilusória sobre a natureza das trocas discursivas intersubjetivas. Mas é presa também de uma hierarquização a priori da legitimidade das formas de ação política, que tem como consequência primordial o bloqueio de estratégias que se mostram, muitas vezes, eficazes para que os grupos dominados obtenham êxito em suas demandas. A "boa" política é aquela que se realiza exclusivamente por meios discursivos e busca alcançar, se não o consenso, pelo menos o acordo mais amplo. A aceitação cada vez mais incondicional da institucionalidade vigente, apontada antes, agrava a situação. A boa política, no final das contas, é aquela que, desenrolando-se em meio às instituições das democracias liberais, contribui para expandir

\footnotetext{
${ }^{8}$ Esse é o ponto decisivo da crítica às teorias do reconhecimento, desenvolvido cuidadosamente por Lois McNay (2008)
} 
seu caráter deliberativo. É este o horizonte normativo que subjaz à maior parte do deliberacionismo atual.

No entanto, as instituições não são neutras. Elas são, em si mesmas, produtos de processos históricos marcados pelas relações de dominação e tendem a funcionar como instrumentos da reprodução desta mesma dominação. Na reflexão política atual, muitas correntes que se desejam "críticas" - e não me refiro apenas ao deliberacionismo - tendem a aceitar a ideia de neutralidade do

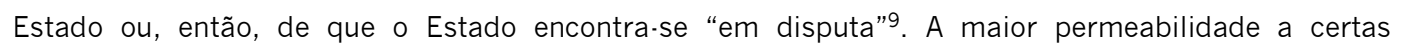
demandas das classes populares ou a multiplicação de "arenas participativas" sustentaria esta percepção. No entanto, a capacidade que os grupos subalternos têm de se fazer ouvir em determinados espaços não implica em neutralidade do Estado. Ele pode ser levado, como efeito das próprias lutas políticas, a permitir "a presença das classes dominadas em seu seio, mas precisamente como classes dominadas" (PoulantZAS, 2013 [1978], p. 210).

O conceito de "seletividade das instituições", presente nos escritos de Claus Offe dos anos 1970, é útil para entender esta dinâmica. Ele mostra que as instituições políticas possuem uma seletividade própria, correspondente aos interesses do processo de valorização do capital, o que se liga à dependência estrutural que os Estados capitalistas possuem em relação à acumulação privada. Assim, alguns tipos de interesses e de demandas são favorecidos, ao passo que outros encontram maior dificuldade para avançar (OFFE, 1984 [1972]).

A aceitação da institucionalidade dada como ambiente definitivo da disputa, só reformável a partir de seus próprios mecanismos, condena os grupos sociais dominados a travar a luta política em condições que Ihes são, de partida, desfavoráveis. Mesmo quando aspectos das instituições políticas são fruto direto das demandas destes grupos, eles tendem a ser acomodados de uma maneira tal que reduz a efetividade das ações transformadoras. O sufrágio universal é um exemplo. Resultado de décadas de lutas de trabalhadores, mulheres e minorias étnicas, ele funciona, em grande medida, como meio de legitimação dos grupos dominantes, capazes de uma influência desproporcional nos resultados eleitorais por conta do controle de recursos materiais, simbólicos e comunicativos, além do próprio Estado.

Ao mesmo tempo, a concessão do direito de voto foi interpretada de maneira a deslegitimar permanentemente estratégias mais ofensivas, muitas vezes também mais eficazes, de manifestação política popular, pois expressão da vontade coletiva por meio eleitoral passou a vigorar como a forma por excelência da soberania coletiva (HIRSCHMAN, 1983 [1982], p. 121-6). Ademais, o modelo liberal de eleição, que convoca cada cidadão a participar como indivíduo isolado, beneficia a expressão de interesses individuais, em detrimento daqueles que precisam ser produzidos coletivamente, como é, em geral, o caso das demandas dos grupos dominados (OFFE e WIESENTHAL, 1984 [1980]).

Tanto quanto a permanência na institucionalidade, a primazia dada às trocas deliberativas age em desfavor dos grupos em posição subalterna. A exigência de consenso ou, ao menos, da obtenção de um compromisso aceitável por todos trabalha objetivamente no sentido da manutenção do

\footnotetext{
${ }^{9}$ Discuti esta questão com maior vagar em outro artigo (MIGUEL, 2014b).
} 
OPINIÃO PÚBLICA, Campinas, vol. 20, n 1, abril, 2014, p. 118-131

status quo, bloqueando a adoção de medidas transformadoras. Em um artigo importante, Iris Marion Young ressaltou a importância do ativismo político para a obtenção de direitos, a despeito do silêncio que a teoria em geral guarda sobre ele. Mas o ativismo não se confunde com a deliberação. Pelo contrário: movidos pelo sentimento de urgência, pela necessidade de superar injustiças e violências que afetam cotidianamente as vidas de inúmeras pessoas, os ativistas muitas vezes buscam interromper o processo de deliberação, clamando por providências imediatas (YounG, 2001, p. 673). Ao mesmo tempo, estão conscientes das maneiras pelas quais as desigualdades históricas estruturam os ambientes de deliberação (YOUNG, 2001, p. 682) ${ }^{10}$.

Para ser eficaz, o ativismo político precisa compreender os limites da institucionalidade vigente e se dispor a forçá-los. Há, aqui, uma compreensão do caráter conflitivo da política que vai muito além da sua incorporação, lateral e domesticada, por parte do novo deliberacionismo. As relações de antagonismo entre dominantes e dominados não se resolvem por consenso, nem por compromisso - o antagonismo é consequência lógica da própria dominação e, para ser superado, exige que ela também o seja.

\section{Conclusão}

Há tempos, em texto polêmico, lan Shapiro (1999) decretou: "Chega de deliberação, política é sobre interesses e poder". Na tentativa de responder a este desafio, a democracia deliberativa reduziu em boa medida suas apostas normativas. Mas o maior realismo alcançado não ficou isento de uma boa dose de acomodação com a ordem existente e de aceitação dos seus limites.

De fato, nos debates dentro da teoria política, a posição realista acaba sendo muitas vezes ocupada pelas perspectivas mais conservadoras. A admissão do caráter inerentemente conflitivo da política (e da centralidade, dentro dela, da disputa entre interesses antagônicos) acaba deslizando para uma abordagem desencantada ou mesmo cínica, em que a política é resumida às relações de força dadas, aceitas como se fossem estáticas. É o maquiavelismo raso e perneta do mainstream da Ciência política - raso porque não conecta os conflitos políticos com as desigualdades sociais e deles nada vê além da disputa pelos cargos de poder; perneta porque aceita de Maquiavel apenas a metade, aderindo ao mito de uma leitura normativamente vazia da política, sem perceber o quanto a obra do escritor florentino era marcada pelo reconhecimento do caráter indeterminado da luta política e pela preocupação com arranjos que reduzissem a dominação.

Empurrada por seus críticos, a democracia deliberativa rompeu com algumas de suas premissas fundadoras, mas não foi capaz de encontrar uma versão que combinasse um realismo sólido com uma recusa igualmente sólida à reificação do mundo existente. Pelo contrário, fica no meio do caminho em ambos os aspectos, fazendo uma aposta excessivamente otimista nas potencialidades emancipatórias da mesma institucionalidade que hoje reproduz as diferentes formas de dominação.

A produção de uma reflexão teórica que seja realista sem cair no conformismo certamente não é fácil. Esse foi (voltando aqui à questão que mobilizou o artigo de Mendonça) o projeto da primeira

\footnotetext{
10 Para uma resenha da literatura deliberacionista sob o ângulo dos imperativos do ativismo, ver Tavares (2012).
} 
geração frankfurtiana. Mas não é o de seus continuadores. No Habermas maduro e em Axel Honneth, impera uma visão idealista da dinâmica social, que pouco elucida seus processos reais e que prima por desconectá-la das formas de dominação e exploração presentes na sociedade. O resultado é a crença de que as mudanças históricas podem ser causadas por "nada além do poder persuasivo - ou melhor, da incontroversibilidade - das razões morais" (HONNETH, 2003, p. 149). Em suma, a escola da "teoria crítica" perdeu seu fôlego crítico e é por isso que a manutenção da fidelidade a ela não implica na manutenção do caráter crítico, no sentido descritivo que apontei antes, em relação ao mundo social.

Creio que o declínio do impulso crítico está vinculado à adesão crescente ao ideal de neutralidade em relação aos interesses em disputa - com o que estas correntes se aproximam do liberalismo contemporâneo. A primazia original dada ao argumento racional tinha esta função, sobretudo na medida em que a razão sempre foi compreendida como um atributo humano universal, descolado das circunstâncias dos sujeitos que a exercem. $O$ argumento racional, por consequência, deve ser neutro diante dos interesses concorrentes. A democracia deliberativa se estabelece igualmente como um conjunto de procedimentos a serem aplicados aos processos de decisão social, sem parti pris - isto é, são procedimentos neutros que levam a resultados legítimos sem beneficiar qualquer dos lados em conflito.

Em sua polêmica com as teorias dominantes da justiça, Iris Marion Young rechaçou a ideia de um padrão universal abstrato e observou que "justiça social significa a eliminação da dominação e da opressão institucionalizadas" (YounG, 1990, p. 16). Creio que é uma lição que pode ser generalizada. Uma teoria crítica não é uma teoria que busca a neutralidade em relação aos conflitos sociais, e sim que assume uma posição vinculada às lutas emancipatórias dos grupos dominados. É essa, mais do que qualquer outra, a característica que a separa das teorias tradicionais. E é essa posição que falta às teorias deliberativas.

É possível dizer que, desde a crise do marxismo, as teorias críticas, no sentido que estou atribuindo ao termo, não possuem um modelo de sociedade para apresentar como alternativa ao existente - já na seara da democracia deliberativa, pelo contrário, há uma quase infinidade de opções. No entanto, o impulso crítico permanece atuante na identificação daquilo contra o que se bate. Esta clareza está ausente do deliberacionismo atual, que, querendo superar seu utopismo de origem, acabou chegando a uma posição complacente com os regimes democráticos concorrenciais e se mostra incapaz de fundar uma ação política voltada à emancipação dos grupos sociais oprimidos.

\section{Referências Bibliográficas}

ALTHUSSER, L. Idéologie et appareils idéologiques d'État (notes pour une recherche). In: Éditions Sociales, 1976. Positions. Paris:

BELL, D. A. Democratic deliberation: the problem of implementation. In: MACEDO, S. (ed.). Deliberative politics: essays on Democracy and disagreement. Oxford: Oxford University Press, 1999. deliberativa. São Paulo: Esfera Pública, 2007 [1994]. 
OPINIÃO PÚBLICA, Campinas, vol. 20, no 1, abril, 2014, p. $118-131$

BICKFORD, S. The dissonance of democracy: listening, conflict, and citizenship. Ithaca: Cornell University Press, 1996. Bohman, J. "The coming age of deliberative democracy". The Journal of Political Philosophy, vol. 6, n 4, p. 400-425, 1998.

BouRdieu, P. La distincton: critique sociale du jugement. Paris: Minuit, 1979.

Le sens pratique. Paris: Minuit, 1980.

Raisons pratiques: sur la théorie de l'action. Paris: Seuil, 1994.

Méditations pascaliennes. Paris: Seuil, 1997.

COHEN, J. Deliberation and democratic legitimacy. In: BOHMAn, J.; REHG, W. (eds.). Deliberative democracy: essays on reason and politics. Cambridge (MA): The MIT Press, 1997.

Cook, D. "The talking cure in Habermas's republic". New Left Review, segunda série, n 12, p. 135.51, 2001.

Dryzek, J. S. Deliberative democracy and beyond: liberals, critics, contestations. Oxford: Oxford University Press, 2000.

Foundations and frontiers of deliberative democracy. Oxford: Oxford University Press, 2010.

FARIA, C. F. "Do ideal ao real: as consequências das mudanças conceituais na teoria deliberativa". Lua Nova, n 87, p.63.81, 2012.

FISHKIN, J. S. The voice of the people: public opinion and democracy. New Haven: Yale University Press, 1997.

FRASER, N. Rethinking the public sphere: a contribution to the critique of actually existing democracy. In: CALHOUn, C. (ed.). Habermas and the public sphere. Cambridge (MA): The MIT Press, 1992.

GinzBURG, C. Olhos de madeira: nove reflexões sobre a distância. São Paulo: Companhia das Letras, 2001 [1998].

HaBermas, J. Mudança estrutural da esfera pública. Rio de Janeiro: Tempo Brasileiro, 1984 [1962].

Consciência moral e agir comunicativo. Rio de Janeiro: Tempo Brasileiro, 1989 [1983].

Direito e democracia: entre facticidade e validade. Rio de Janeiro: Tempo Brasileiro, 1997 [1992].

Teoría de la acción comunicativa, 2 vol. Madrid: Taurus, 2008 [1981].

HIRSCHMAN, A. O. De consumidor a cidadão: atividade privada e participação na vida pública. São Paulo: Brasiliense, 1983 [1982].

HONNETH, A. Redistribution as recognition: a response to Nancy Fraser. In: Fraser, N.; HONNETH, A. Redistribution or recognition? A political-philosophical exchange. London: Verso, 2003.

MacKinnon, C. A. Toward a feminist theory of the State. Cambridge (MA): Harvard Universiry Press, 1989.

MANSBRIDGE, J. et al. A systemic approach to deliberative democracy. In: PARKInSON, J.; MANSBRIDGE, J. (eds.).

Deliberative systems: deliberative democracy at the large scale. Cambridge: Cambridge University Press, 2012.

MARQUES, F. P. J. A. "Debates políticos na internet: a perspectiva da conversação civil”. Opinião Pública, vol. 12, n 1, p. 164-187, 2006.

McNay, L. Against recognition. Cambridge: Polity, 2008.

Mendonça, R. F. "Teoria crítica e democracia deliberativa: diálogos instáveis". Opinião Pública, vol. 19, n 1, p. 49.64, 2013.

; CAL, D. G. "Quem pode falar no Facebook? O autocontrole em um grupo sobre o plebiscito acerca da divisão do Estado do Pará". Revista Debates, vol. 6, n³, p. 109-128, 2012.

; PereiRA, M. A. "Democracia digital e deliberação online: um estudo de caso sobre o VotenaWeb". Revista Latinoamericana de Opinión Pública, n² 2, p. 109-158, 2012.

Miguel, L. F. "As duas lógicas da ação comunicativa: democracia e deliberação no debate contemporâneo". Teoria \& Sociedade, $n^{\circ} 10$, p. 104-143, 2002. 

Ciências Sociais, $n^{\circ}$ 59, p. 5.42, 2005.

2011.

"Representação democrática: autonomia e interesse ou identidade e advocacy". Lua Nova, n 84, p. 25.63,

Democracia e representação: territórios em disputa. São Paulo: Editora Unesp, 2014a.

"Mecanismos de exclusão política e os limites da democracia liberal: uma conversa com Poulantzas, Offe e Bourdieu". Novos Estudos Cebrap, n 98, no prelo, 2014b.

OfFE, C. Dominação de classe e sistema político. Sobre a seletividade das instituições políticas. In: Problemas estruturais do Estado capitalista. Rio de Janeiro: Tempo Brasileiro, 1984 [1972].

.; WiesentHAL, H. (1984 [1980]). Duas lógicas da ação coletiva: anotações teóricas sobre classe social e forma organizacional. In: OfFE, C. Problemas estruturais do Estado capitalista. Rio de Janeiro: Tempo Brasileiro, 1984 [1980].

PoulantZAS, N. L'État, le pouvoir, le socialisme. Paris: Le Prairies Ordinaires, 2013 [1978].

RawLS, J. Political liberalism. Expanded edition. New York: Columbia University Press, 2005 [1993].

SAMPAIO, R. C.; BARROS, S. A. R.; MoRAIS, R. "Como avaliar a deliberação online? Um mapeamento de critérios relevantes". Opinião Pública, vol. 18, n² 2, p. 470.489, 2012.

Sampaio, R. C.; MaiA, R. C. M.; MARQues, F. P. J. A. "Participação e deliberação na internet: Um estudo de caso do Orçamento Participativo Digital de Belo Horizonte". Opinião Pública, vol. 16, n² 2, p. 446.477, 2010.

SANDERS, L. "Against deliberation". Political Theory, vol. 25, n 3, p. 347-376, 1997.

SCHEUERMAN, W. E. Between radicalism and resignation: democratic theory in Habermas's Between facts and norms. In: DEws, P. (ed.). Habermas: a critical reader. Oxford: Blackwell, 1999.

SHAPIRO, I. Enough of deliberation: politics is about interests and power. In: MACEDO, S. (ed.). Deliberative politics: essays on Democracy and disagreement. Oxford: Oxford University Press, 1999.

TAvares, F. M. M. "Em busca da deliberação: mecanismos de inserção das vozes subalternas no espaço público". Revista Brasileira de Ciência Política, n 9, p. 39-70, 2012.

Young, I. M. Justice and the politics of difference. Princeton: Princeton University Press, 1990.

Inclusion and democracy. Oxford: Oxford University Press, 2000.

"Activist challenges to deliberative democracy". Political Theory, vol. 29, n 5. p. 670-690, 2001.

Luis Felipe Miguel · luisfelipemiguel@gmail.com

Recebido para publicação em outubro de 2013.

Aprovado para publicação em outubro de 2013. 